\title{
Plastic Deformation in Profile-Coated Elliptical KB Mirrors
}

\author{
Chian Liu, ${ }^{1}$ R. Conley, ${ }^{2}$ J. Qian, ${ }^{1}$ C. M. Kewish, ${ }^{3}$ W. Liu, ${ }^{1}$ L. Assoufid, ${ }^{1}$ A. T. Macrander, ${ }^{1}$ \\ G. E. Ice, ${ }^{4}$ and J. Z. Tischler ${ }^{1}$ \\ ${ }^{1}$ X-ray Science Division, Argonne National Laboratory, Argonne, IL 60439, USA \\ ${ }^{2}$ National Synchrotron Light Source II, Brookhaven National Laboratory, Upton, NY 11973, USA \\ ${ }^{3}$ Synchrotron Soleil, BP 48 Saint-Aubin, 91192 Gif-sur-Yvette, France \\ ${ }^{4}$ Materials Science and Technology Division, Oak Ridge National Laboratory, Oak Ridge, TN 37831, USA \\ Correspondence should be addressed to Chian Liu, cliu@aps.anl.gov
}

Received 19 July 2012; Accepted 8 August 2012

Academic Editors: K. Hane and S. R. Restaino

Copyright ( $\odot 2012$ Chian Liu et al. This is an open access article distributed under the Creative Commons Attribution License, which permits unrestricted use, distribution, and reproduction in any medium, provided the original work is properly cited.

Profile coating has been successfully applied to produce elliptical Kirkpatrick-Baez (KB) mirrors using both cylindrical and flat Si substrates. Previously, focusing widths of $70 \mathrm{~nm}$ with $15-\mathrm{keV}$ monochromatic and $80 \mathrm{~nm}$ with white beam were achieved using a flat Si substrate. Now, precision elliptical KB mirrors with sub-nm figure errors are produced with both Au and Pt coatings on flat substrates. Recent studies of bare $\mathrm{Si}-, \mathrm{Au}-$, and Pt-coated $\mathrm{KB}$ mirrors under prolonged synchrotron X-ray radiation and low-temperature vacuum annealing will be discussed in terms of film stress relaxation and Si plastic deformation.

\section{Introduction}

It has long been recognized that mirror figure can be modified by controlled thin-film deposition $[1,2]$. We have developed a profile-coating technique to make ultraprecise elliptical mirrors for X-ray microfocusing [3, 4]. Elliptical $\mathrm{KB}$ mirrors with sub-nm figure errors can now be produced using flat Si substrates with only two profile coatings. Sub$100-\mathrm{nm}$ focusing has been demonstrated using a synchrotron X-ray beamline [5]. Nested KB mirrors have also been successfully fabricated $[6,7]$. One serious concern of X-ray mirrors is their long-term figure stability. We have noticed changes in mirror figure during prolonged $\mathrm{X}$-ray irradiation when the mirror is too thin and narrow. The observed changes are believed to result from plastic deformation of profile-coated $\mathrm{KB}$ mirrors. This plastic deformation is a surprise since in our applications there is very little heat load on each $\mathrm{KB}$ mirror and the Si substrate has a brittle-ductile transition of $847^{\circ} \mathrm{C}[8]$.

The plastic deformation may be related to film stress introduced during coatings. The film stress can be relaxed at temperatures as low as a few hundred degrees $C$ [9]. We found that low-temperature vacuum annealing can cause plastic deformation similar to that introduced by prolonged $\mathrm{X}$-ray radiation in profile-coated $\mathrm{KB}$ mirrors. To overcome this plastic deformation, we need to optimize the mirror dimensions to improve mechanical stability and to decrease the film stress.

\section{Recent Results of Au- and Pt-Coated KB Mirrors Using Flat Si Substrates}

Precision elliptical KB mirrors with sub-nm figure errors have been fabricated with a predicted focal spot of $38.9 \mathrm{~nm}$ (FWHM), compared to the diffraction limit of $37.8 \mathrm{~nm}$ for a perfect ellipse [10]. On the 34-ID beamline at the Advanced Photon Source of Argonne National Laboratory, an Auprofile-coated $\mathrm{KB}$ pair, with dimensions of $70-\mathrm{mm} \mathrm{L} \times 9$ $\mathrm{mm} \mathrm{W} \times 4.5-\mathrm{mm} \mathrm{H}$ and $40-\mathrm{mm} \mathrm{L} \times 10-\mathrm{mm} \mathrm{W} \times 20-\mathrm{mm} \mathrm{H}$, has produced $\sim 0.60 \times 0.40 \mu \mathrm{m}^{2}$ focused white beams for several years under normal conditions until it was recently subjected to prolonged $\mathrm{X}$-ray radiation continuously with the slits fully open for several days. After this exposure, the $\mathrm{KB}$ pair performance degraded so severely that it could no longer be used for microfocusing. 


\section{Extended Synchrotron Radiation and Low-Temperature Annealing Tests}

One of the damaged mirrors, the $70 \mathrm{~mm}$ long one, was remeasured using microstitching interferometry. The mirror was coated with a uniform $15 \mathrm{~nm}$ thick $\mathrm{Cr}$ underlayer and an Au-profiled layer with thicknesses varying from $100 \mathrm{~nm}$ in the center to over $6 \mu \mathrm{m}$ at the ends. The surface profiles before and after the extended X-ray radiation are shown in Figure 1(a). The profiles overlap with each other, but their height difference shows a clear upward, concaved profile change. The maximum deflection at the center of the mirror is $\sim 140 \mathrm{~nm}$. Another similar profile-coated KB mirror was annealed at $350^{\circ} \mathrm{C}$ for $15 \mathrm{~min}$ and measured before and after annealing, with results shown in Figure 1(b). An upward profile change is also evident after the annealing, with a maximum deflection of $\sim 175 \mathrm{~nm}$.

We repeated the same annealing procedure for a bare $\mathrm{Si}$ substrate, an $\mathrm{Au}$ - and a Pt-profile-coated mirror, with the same dimensions of 70- $\mathrm{mm} \mathrm{L} \times 9-\mathrm{mm} \mathrm{W} \times 4.5-\mathrm{mm} \mathrm{H}$. All samples were annealed three times with their surface profiles measured after each annealing and compared to that before each annealing. The maximum deflection results were plotted as shown in Figure 2. After the first annealing, they all had an upward concave profile change, with the Aucoated one changed the most. After the second annealing, the changes were all smaller. For Au-coated and bare Si, the profile change became convex. The third annealing had very little effect for all three samples.

\section{Discussions}

When flat substrates are used for profile coating of $\mathrm{KB}$ mirrors the film stress becomes a significant problem. For mirror application, an ultrasmooth, highly reflective coating is needed, which is often achieved using growth conditions with a low Ar pressure and a low substrate temperature. A large film stress is expected under these conditions [11] and will bend the substrate. For a wafer substrate the curvature change due to film stress is proportional to $\left[t_{f}\right] /\left[t_{s}\right]^{2}$, where $\left[t_{f}\right]$ and $\left[t_{s}\right]$ are the film and the substrate thickness, respectively [12]. When the substrate is relatively thin and narrow, a film stress relaxation [11] can change the surface profile. A high film stress may also induce defect movements in the underlying $\mathrm{Si}$ at low activation energies, leading to plastic deformation in the substrate $[13,14]$. The film stress relaxation is believed to be due to a diffusive relief of compressive stresses [9]. A film with a lower stress is expected to have a lower stress relaxation. Pt has a relatively smaller thermal expansion coefficient than $\mathrm{Au}$ and thus a smaller thermal stress, which may attribute to the observed differences in a smaller stress relaxation (Figure 2). The bare Si substrate also has a surface stress due to a compression of the surface layer during polishing $[15,16]$. For chemicalmechanical polished substrates, the surface stress is relatively small and decreases rapidly with annealing. This smaller stress explains the smaller deflection for the bare Si substrate as shown in Figure 2.
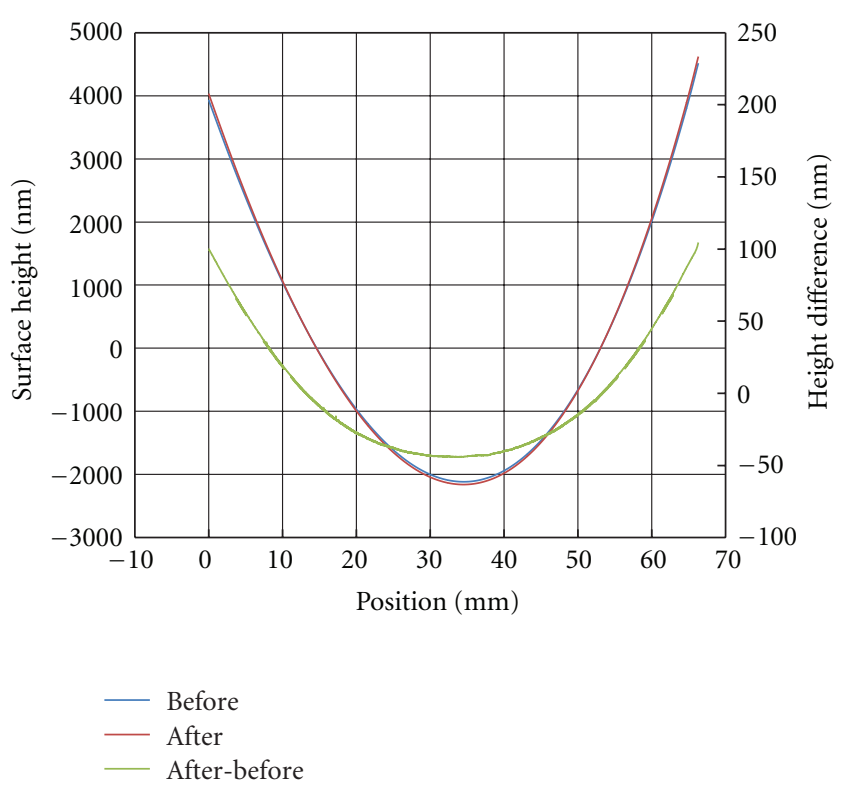

(a)

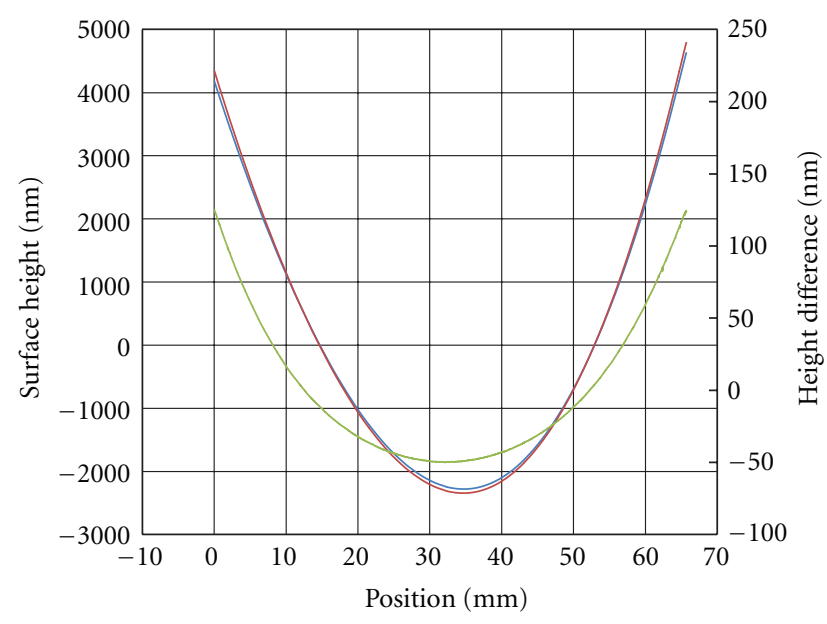

- Before
- After
- After-before

(b)

FIGURE 1: Surface profiles before and after: (a) the prolonged Xray radiation and (b) low-temperature annealing. A clear upward, concave profile change can be seen in both (a) and (b) from the height difference data. The maximum deflection at the center is $\sim 140 \mathrm{~nm}$ in (a) and $\sim 175 \mathrm{~nm}$ in (b).

The plastic deformation of the profile-coated $\mathrm{KB}$ mirrors under prolonged X-ray irradiation may also be due to film stress relaxation. It is known that the dominant absorption mechanism of the X-ray energy is photoionization in a thin surface layer [17]. This surface effect may be sufficient to cause a stress relaxation in the $\mathrm{Au}$ film without a noticeable increase in the mirror temperature. The surface photoionization under extended X-ray radiation may cause 


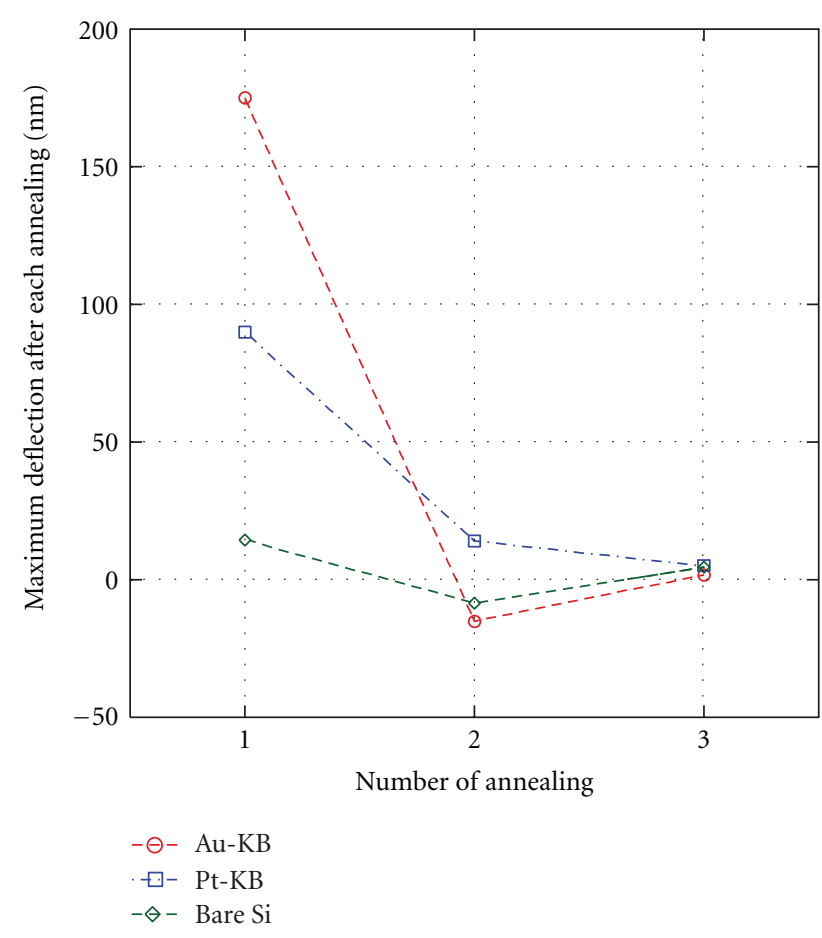

Figure 2: The maximum deflection at the center of the sample after each annealing for $\mathrm{Au}$ - and Pt-profile-coated KB mirrors, and a bare Si substrate. All three samples have the same physical dimensions. A positive number indicates an upward (concave) profile change and a negative one a downward (convex) change.

the same effect in the coated film as observed in lowtemperature annealing. To make the mirror more stable, we need to use thicker substrates and decrease the film stress. One may choose coating materials with a smaller film stress, or coat only a strip on the mirror instead of coating the whole surface. Low-temperature annealing before the final corrective coating should also be helpful, even though the annealing temperature is limited by crystallization in the thick film. One may use spherical substrates so that less coating is needed. However, only a small region close to the center line can be coated precisely according to the design parameters due to the spherical shape of the substrate. In this case, a profile-figured substrate would be a much better choice. Currently, a profile-etching technique is under development to make such substrates using a broad beam ion source [18].

\section{Acknowledgments}

The authors would like to thank M. Wieczorek and J. Attig from Argonne National Laboratory for technical assistance. Work at Argonne was supported by the US Department of Energy, Office of Science, Office of Basic Energy Sciences, under Contract no. DE-AC02-06CH11357. G. E. Ice and J. Z. Tischler were supported by the DOE Office ofBasic Energy Sciences, Department of Materials Sciences and Engineering. R. Conley and C. M. Kewish were at Argonne and J. Z. Tischler was at Oak Ridge National Laboratory when this work was done.

\section{References}

[1] J. Strong and E. Gaviola, "On the figuring and correcting of mirrors by controlled deposition of aluminum," Journal of the Optical Society of America, vol. 26, no. 4, p. 153, 1936.

[2] J. R. Kurdock and R. R. Austin, "Correction of optical elements by the addition of evaporated films," in Physics of Thin Films, vol. 10, pp. 261-308, 1978.

[3] C. Liu, L. Assoufid, R. Conley, A. T. Macrander, G. E. Ice, and J. Z. Tischler, "Profile coating and its application for Kirkpatrick-Baez mirrors," Optical Engineering, vol. 42, no. 12, pp. 3622-3628, 2003.

[4] C. Liu, R. Conley, L. Assoufid, Z. Cai, J. Qian, and A. T. Macrander, "From flat substrate to elliptical KB mirror by profile coating," AIP Conference Proceedings, vol. 705, pp. 704$707,2004$.

[5] W. Liu, G. E. Ice, J. Z. Tischler et al., "Short focal length Kirkpatrick-Baez mirrors for a hard x-ray nanoprobe," Review of Scientific Instruments, vol. 76, no. 11, Article ID 113701, 6 pages, 2005.

[6] C. Liu, G. E. Ice, W. Liu et al., "Fabrication of nested elliptical $\mathrm{KB}$ mirrors using profile coating for synchrotron radiation $\mathrm{X}$ ray focusing," Applied Surface Science, vol. 258, no. 6, pp. 21822186, 2012.

[7] W. Liu, G. E. Ice, L. Assoufid et al., "Achromatic nested Kirkpatrick-Baez mirror optics for hard x-ray nanofocusing," Journal of Synchrotron Radiation, vol. 18, no. 4, pp. 575-579, 2011.

[8] H. Siethoff, "Macroscopic mechanical behaviour of Si at high temperature," in Properties of Crystalline Silicon, R. Hull, Ed., p. 122, INSPEC, London, UK, 1999.

[9] D. J. Quinn, B. Wardle, and S. M. Spearing, "Residual stress and microstructure of as-deposited and annealed, sputtered yttria-stabilized zirconia thin films," Journal of Materials Research, vol. 23, no. 3, pp. 609-618, 2008.

[10] C. M. Kewish, L. Assoufid, A. T. Macrander, and J. Qian, "Wave-optical simulation of hard-x-ray nanofocusing by precisely figured elliptical mirrors," Applied Optics, vol. 46, no. 11, pp. 2010-2021, 2007.

[11] J. A. Thornton and D. W. Hoffman, "Stress-related effects in thin films," Thin Solid Films, vol. 171, no. 1, pp. 5-31, 1989.

[12] G. Stoney, "The tension of metallic films deposited by electrolysis," Proceedings of the Royal Society A, vol. 82, no. 553, pp. 172-175, 1909.

[13] N. E. B. Cowern, "Diffusion in a single crystal within a stressed environment," Physical Review Letters, vol. 99, no. 15, Article ID 155903, 4 pages, 2007.

[14] J. Babier and J. L. Demenet, "Low temperature, high stress plastic deformation of semiconductors: the silicon case," Physica Status Solidi B, vol. 222, no. 1, pp. 63-74, 2000.

[15] D. Golini and S. D. Jacobs, "Physics of loose abrasive microgrinding," Applied Optics, vol. 30, no. 19, pp. 2761-2777, 1991.

[16] D. Haneman, M. F. Chung, and A. Taloni, "Comparison of thermal behavior of vacuum-crushed, air-crushed, and mechanically polished silicon surfaces by electron paramagnetic resonance," Physical Review, vol. 170, no. 3, pp. 719-723, 1968.

[17] D. D. Ryutov, "Thermal stresses in the reflective $\mathrm{x}$-ray optics for the Linac Coherent Light Source," Review of Scientific Instruments, vol. 74, no. 8, p. 3722, 2003.

[18] C. Liu, "Ion beam profile etching," Invention Report ANL-IN12-015, 2012. 

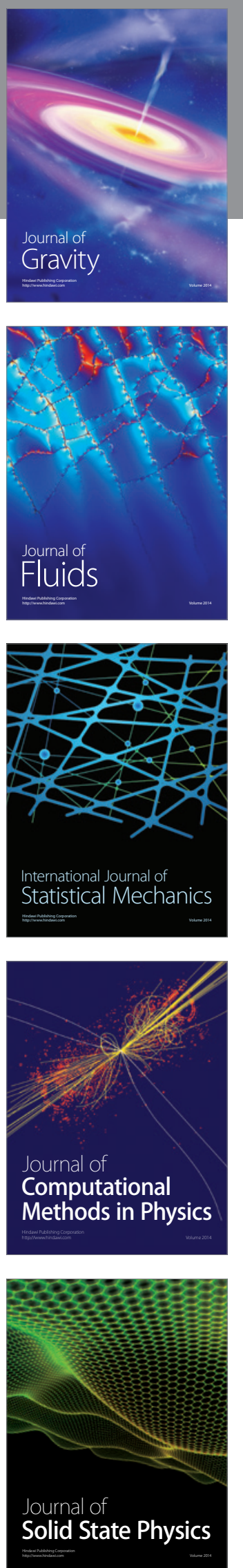
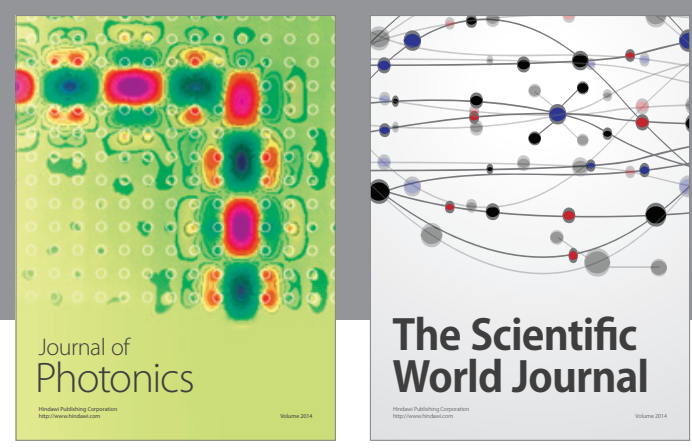

The Scientific World Journal

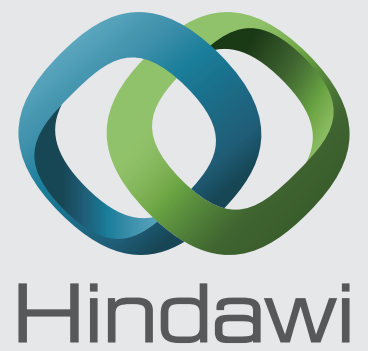

Submit your manuscripts at http://www.hindawi.com
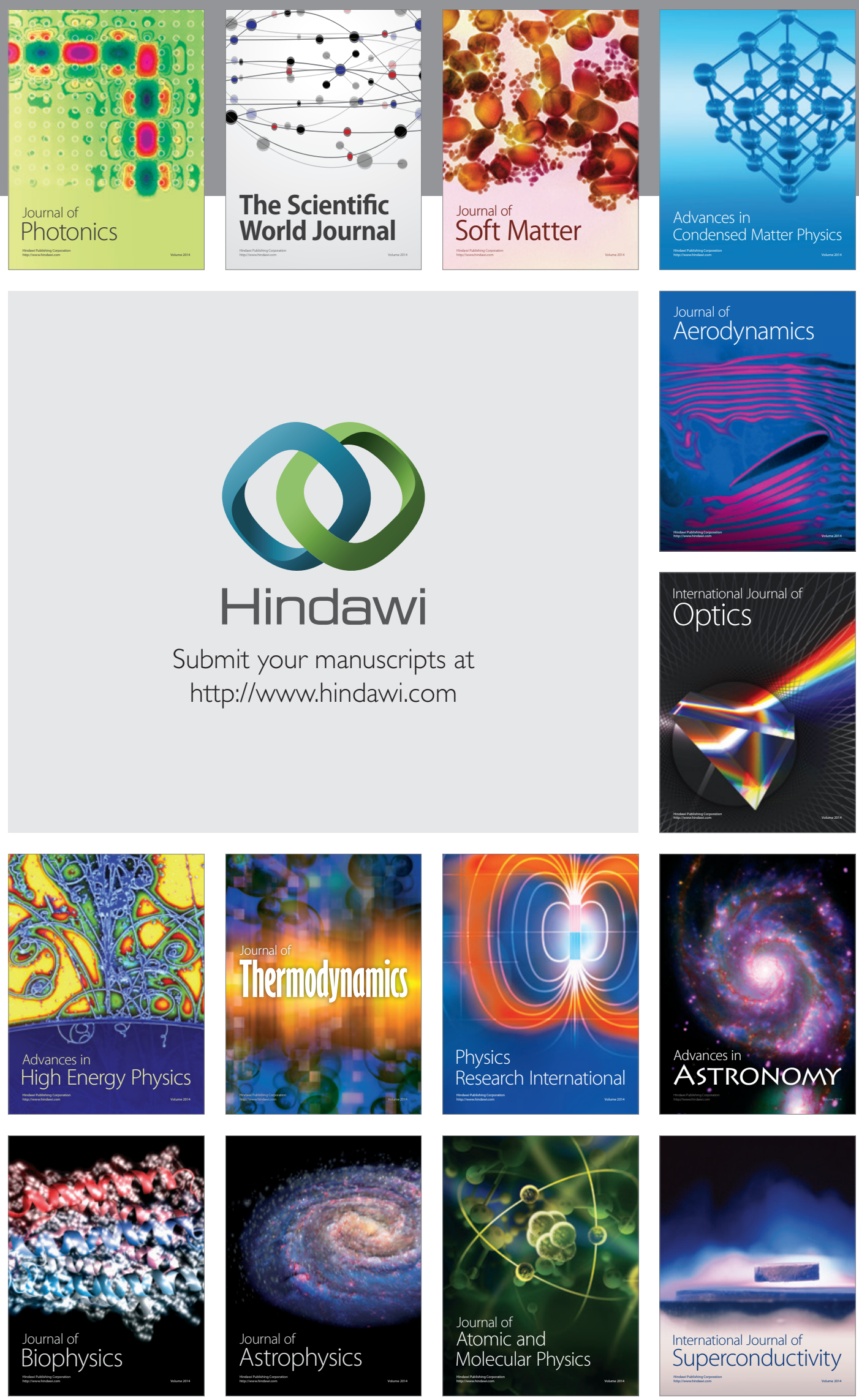
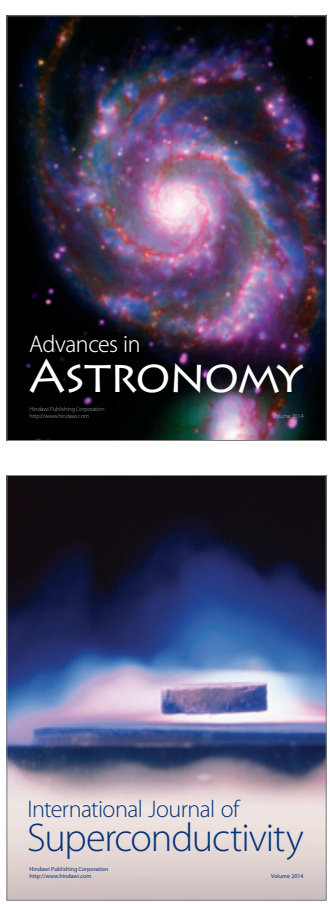